\title{
DON JUAN MANUEL MONTENEGRO Y EL MUNDO SOCIAL DE LAS COMEDIAS BÁRBARAS (CONSTRUCCIÓN Y SENTIDO DE UN PERSONAJE VALLEINCLANIANO)
}

\author{
Margarita Santos Zas \\ Universidad de Santiago de Compostela
}

Mostrar el papel y sentido que don Juan Manuel Montenegro alcanza en las Comedias Bárbaras, es el último eslabón de una cadena que remite a su génesis. Y siendo esta figura una de las más emblemáticas del mundo literario de Valle-Inclán, su proceso de construcción permitirá, a su vez, aproximarnos al sistema de creación del escritor.

Don Juan Manuel Montenegro no nace como Atenea de la cabeza de Zeus -armada con todas sus armas-, sino que se va perfilando paulatinamente'. A lo largo de esa trayectoria el personaje va adquiriendo singular magnitud hasta el punto de convertirse en el símbolo de un mundo que con él se extingue: el del Antiguo Régimen en el que se inscribe la vieja y tradicional nobleza rural, que la figura de Montenegro encarna de forma paradigmática.

Por vez primera aparece su nombre en un cuento de 1895, "Rosarito". Años más tarde volvemos a encontrarlo en la Sonata de Otoño (1902), más fugazmente -una leve mención- en la de Invierno (1905), y poco después en El Marqués de Bradomín, Coloquios románticos, pieza dramática estrenada en 1906. Pero el personaje no alcanzará su perfil definitivo hasta la primera de las obras que componen la trilogía de las Comedias Bárbaras, Aguila de Blasón (1907), convertido en su protagonista. Protagonismo que perdura en los restantes textos que componen dicha trilogía: Romance de Lobos (1908) y Cara de Plata (1922). Por fin, DJMM reaparece en otra obra de Valle-Inclán, esta vez perteneciente a una serie narrativa de carácter histórico, Los Cruzados de la Causa (1908), título inicial de la trilogía bélica La Guerra Carlista.

El retorno del personaje: así se ha denominado con expresiva fórmula esta reiterada presencia. Siguiendo este sistema, que cuenta con diversos antecedentes en nuestra literatura (recuérdese, entre otros, el caso de Galdós), Valle-Inclán a la hora de configurar a sus personajes y, en concreto, a DJMM, se vale de rasgos empleados previamente para su caracterización, de manera que en sus sucesivas reapariciones los datos anteriores operan por asociación de forma prácticamente automática sobre la mente del lector avezado. Así, pues, para la eficacia de estas recurrencias el autor cuenta con la cooperación del lector y crea entre éste y el texto una complicidad que reside tanto en el poder de sugerencia de su palabra poética, como en la capacidad de evocación de las situaciones protagonizadas en otras obras, hasta el punto de que estos personajes -ya lo observó Alfonso Reyes- van adquiriendo un auténtico pasado personal. El caso de Montenegro es modélico de este sistema de creación. Pero no es el único. 
Otras criaturas valleinclanianas con nombre propio aparecen, desaparecen y reaparecen en contextos casi siempre afines por su temática y ambientación espacio-temporal. Tal sucede con algunas figuras secundarias que cruzan repetidas veces el universo literario del escritor (Don Galán, Sabelita, el Sr. Ginero, Agila Palafox, Eulalia, el Duque de Ordax...). O tan emblemáticas como el Marqués de Bradomín, el decadente Don Juan de las cuatro Sonatas, al que Valle fue dibujando desde sus primeros cuentos para hacer de él en las novelas de La Guerra Carlista un convencido "cruzado de la causa" tradicionalista, a la que consagra el entusiasmo militante que en su "autobiografía ficticia" había aplicado a la seducción de mujeres. Con esos ribetes político-partidistas, ingrediente de su personalidad ya en las citadas Sonatas, volvemos a toparlo en Una Tertulia de Antaño y en las últimas novelas de Valle-Inclán, las del inconcluso ciclo de El Ruedo Ibérico, tras una fugaz presencia en Luces de Bohemia en compañía esta vez de un personaje real al que Valle profesaba rendida admiración: Rubén Darío. Es así que podemos perseguir la figura de Xavier de Bradomín desde el inicio hasta el final de la obra de don Ramón.

La reaparición del personaje no solo dota a la criatura literaria de una fuerte autonomía: el personaje adquiere ante los ojos del lector vida propia, sino que confiere cohesión interna al microcosmos literario del escritor. Los personajes tienen la capacidad de crear una especie de diálogo intertextual, que exige, por su parte, un lector cómplice. Pero no son solamente los personajes quienes contribuyen a este fecundo diálogo. La obra de Valle se construye en buena parte a base de recurrencias temáticas y crono-espaciales, que el lector, a medida que se interna en la aventura de leer, va encajando a modo de piezas sueltas de un gran "puzzle". Así pues, Valle juega con los materiales de sus obras para la recreación de un nuevo universo de ficción².

Los ejemplos podrían multiplicarse, pero me voy a servir de Juan Manuel Montenegro, rastreando su configuración hasta situarlo en el contexto de las Comedias Bárbaras, que le da sentido pleno $^{3}$, y averiguar el papel que en ellas desempeña. Vuelvo, por tanto, al principio de esta exposición.

La imagen del Juan Manuel Montenegro del cuento Rosarito ${ }^{4}$ coincide sólo parcialmente con la que ofrece Valle-Inclán en Comedias Bárbaras. Montenegro en ese relato temprano encarna un prototipo masculino: el seductor, tipificación del clásico don Juan y partícipe de las características de irreverencia, libertinaje y espíritu aventurero de sus predecesores. Esa función dominante desencadena en el cuento la trágica muerte de la jovencísima, casi niña, Rosarito, inducida o realizada -el desenlace es ambiguo- por el maduro galán.

Pero este papel va acompañado de otras notas que completan su personalidad. Don Juan Manuel pertenece a la antigua nobleza gallega, un linaje del que se siente orgulloso en su fuero interno, si bien presume despreciarlo, porque el personaje es presentado como "liberal aforrado en masón" (p. 155). Ese liberalismo ideológico justifica su situación de "exiliado" en Portugal, su presencia clandestina en el pazo gallego de su prima, la anciana Condesa de Cela, abuela de Rosarito, y su posterior huída, tras la oscura muerte de su víctima.

Valle-Inclán ha creado a un personaje cuya imagen física aparece en esta primera ocasión prácticamente fijada: es “el varonil y hermoso tipo suevo tan frecuente en los hidalgos de la montaña gallega” (p. 153); también su rango social: la privilegiada nobleza decimonónica. Pero el JMM de "Rosarito" es calificado como "liberal" y este rasgo marca una diferencia esencial con su imagen ulterior. 
Es decir, de la figura fraguada inicialmente, don Ramón conservará características físicas, rasgos del carácter y su capacidad seductora, pero no su filiación política a la que en el cuento asocia sus contradictorias actitudes y, en cierto modo, atribuye también su censurable acción. Tal vez por ello en las ediciones del cuento, posteriores a la publicación de las Comedias Bárbaras, cambia su nombre: DJMM se llamará a partir de 1914 Miguel Bendaña o Miguel Montenegro 5 .

Mucho más próximo al perfil definitivo de DJM está el que Valle-Inclán nos brinda en la pieza teatral El Marqués de Bradomín. Coloquios románticos, estrenada en el madrileño teatro Princesa el 25 de enero de $1906^{6}$. Se trata de un texto construido a base de materiales de las Sonatas, en particular de la de Otoño, que anticipa rasgos del personaje, y la de Invierno, a los que se añaden ingredientes que proceden de Flor de Santidad, Rosarito y Eulalia. Esta peculiaridad constructiva -es una pieza-collage ${ }^{7}$ - explica la presencia recurrente de temas, motivos y personajes de las obras citadas. Pero además, y esto es muy significativo para lo que pretendo mostrar, hay que destacar su condición de preámbulo de las Comedias Bárbaras, no solo por lo que se refiere al género, sino por lo que respecta al contenido, ya que anuncia algunos de los aspectos y motivos temáticos más significativos del nuevo ciclo.

Dicho en pocas palabras, en $M B C R$ se ofrece una visión estamentalista de la sociedad gallega, de ahí que las relaciones sociales sean las propias del mundo precapitalista, en el que la aristocracia ocupa la cúspide de una pirámide social cuya base es un pueblo de campesinos, criados y mendigos que mantienen relaciones de servidumbre con el señor.

En este marco se encuadra, en un papel secundario, DJMM, que pertenece a uno de los más ilustres linajes españoles. Los Montenegro descienden de "una emperatriz alemana" y su escudo "Es el único blasón que lleva metal sobre metal: espuelas de oro en campo de plata" (p. 112).

Este culto hacia el pasado -un pasado lleno de señorío y grandeza- y sus formas de vida entra en conflicto con una nueva realidad histórica que convierte a DJM "en el último superviviente de una gran raza"(p. 93). No obstante, Montenegro conserva, como anacrónica reminiscencia de su antiguo poderío, gestos, actitudes y atribuciones de señor feudal: "Vive rodeado de criados que no puede pagar, haciendo la vida de todos los mayorazgos campesinos" (p. 92); y como antaño ejerce sus tradicionales funciones de padre-amo-juez en esta sociedad jerárquica.

Don Juan Manuel Montenegro, representante por antonomasia de la rancia y arruinada hidalguía, anuncia en esta obra el papel que va a desempeñar en las Comedias Bárbaras, en las que en adelante me centraré.

La primera de ellas, Aguila de Blasón, sale de la imprenta en $1907^{8}$, tras un complejo proceso de creación ${ }^{9}$, del que forma parte una larga prehistoria de antetextos y una versión inacabada en forma de folletín publicada en España Nueva en $1906^{10}$.

En cuanto a Romance de Lobos su gestación es más sencilla, ya que apareció tan solo una versión en el periódico El Mundo, entre el 21 de octubre y el 26 de diciembre de 1907, previa a la definitiva de $1908^{11}$.

Finalmente, quince años después de publicados ambos textos Valle da a la imprenta el tercero, Cara de Plata, cuya primera versión publicó la revista La Pluma entre julio y diciembre de 1922 y, al año siguiente, se editó como vol. XIII de la Opera Omnia (Renacimiento, Madrid). 
Por lo que respecta a esta obra, es claro que Valle-Inclán después de haber escrito Romance de Lobos, cuya acción concluye con la muerte de DJMM, no podía ampliar su trilogía en esta dirección. Tenía que invertir el camino, o sea: dramatizar los precedentes lejanos de este desenlace. Se justifica así que Cara de Plata, siendo cronológicamente la última de las tres obras, inaugure argumentalmente el ciclo dramático.

Conviene añadir sin embargo -y me limito simplemente a apuntarlo ${ }^{12}$ - que los tres lustros transcurridos entre esta última comedia bárbara y las dos primeras no pasaron en vano. Cara de Plata acusa el peso de la nueva orientación estética de Valle-Inclán, implícita en el concepto de "esperpento" -definido en 1920- a pesar del intento del escritor por adecuarla al tono y estilo de las anteriores.

Hecha esta salvedad, las $C B$ vuelven a constituir un buen ejemplo del citado sistema de creación valleinclaniano, ya que retoman personajes, situaciones, ambientes y temas de obras anteriores que tienen aquí un desarrollo más amplio y, al mismo tiempo, genera otros que, a su vez, pasarán a las posteriores. De esta forma, la obra de Valle crea un entramado de relaciones dinámicas que se amplifican y transforman de unas a otras.

Desde esta óptica es importante subrayar que la $1^{\text {a }}$ versión de Aguila de Blasón nos proporciona la indicación de lugar y tiempo en el que se sitúa la acción: "Viana del Prior hace treinta años"13. Es decir, Galicia en 1876. Esta precisión, aunque suprimida en las ediciones posteriores a 1906, tiene un interés indudable.

En primer lugar, la fecha de 1876 nos sitúa en un momento histórico común al de Sonata de Invierno y muy próximo al de Marqués de Bradomín, que, asimismo, será el marco de La Guerra Carlista. En segundo lugar, esa localización en un espacio gallego, aunque imaginario en su ubicación geográfica (Viana del Prior no existe), explica su particular afinidad con $E l$ Marqués de Bradomín y Los Cruzados de la Causa, cuyos episodios también se ubican en esa región del Noroeste de España. Finalmente, lo que es más importante, esa precisión crono-espacial permite determinar las relaciones entre un mundo histórico concreto -el de Galicia en el último tercio del siglo XIX-y su proyección artístico-literaria ${ }^{14}$.

En el conjunto de las $C B$ Valle refleja un momento de cambio social, el paso de la sociedad del Antiguo Régimen a la nueva: burguesa, capitalista y liberal. En ellas recrea la lucha entre un mundo que se resiste a morir -el de los últimos hidalgos supervivientes de la abolición de los señoríos y mayorazgos-, y el de la burguesía que pugna por nacer. Entre ambos aparecen las generaciones más jóvenes convulsionadas y desarraigadas por el cambio.

Como entramado, soporte y marco de este tema ofrece un amplio cuadro de la Galicia rústica decimonónica: semifeudal, de economía precapitalista, en la que perduran legislaciones e instituciones antiguas y cuya rigurosa organización estamental empieza a resquebrajarse ante el empuje de la incipiente sociedad capitalista. Una Galicia, pues, en lo social, económico y jurídico profundamente tradicional, arcaica, pero no anacrónica, ya que Valle premeditadamente elige una de esas regiones donde el tiempo histórico avanza a un ritmo mucho más lento que en otras zonas de España: Galicia mantiene en parte vigentes en 1876 esas formas de vida desarrolladas literariamente por el escritor en sus Comedias Bárbaras. Una sociedad, en suma, que no ha dado el salto a la modernidad, pero que sufre los efectos de la revolución burguesa.

En este contexto, el escritor concentra su atención sobre una comunidad rural ficticia y, concretamente, sobre la figura del hidalgo, último destello de un mundo pasado recordado con nostalgia: 
He asistido al cambio de una sociedad de castas (los hidalgos que conocí de rapaz), y lo que yo vi no lo verá nadie. Soy el historiador de un mundo que acabó conmigo. Ya nadie volverá a ver vinculeros y mayorazgos. Y en este mundo que yo presento de clérigos, mendigos, putas y alcahuetas, lo mejor -con todos sus vicios- eran los hidalgos, lo desaparecido ${ }^{15}$.

Este comentario de Valle, si bien no implica la estimación de su autor como historiador sensu strictu ${ }^{16}$, ofrece inequívocamente su afán testimonialista. Es decir, Valle se enfrenta retrospectivavemente a una sociedad -la suya en 1876- y muestra "desde dentro" la visión de un mundo que conoce y del que forma parte. Es más, ese pasado en la misma medida en que se añora, sigue vivo para Valle-Inclán.

A lo largo de las páginas de las $C B$ observamos una sociedad estamental, cuya cúspide ocupan los "señores", sector dominante, junto con la Iglesia, en lo económico y social. A dicho sector pertenecen los viejos hidalgos de pazos y casonas, de los que don JMM es modélico ejemplar.

Valle a través de un caso individual, el de Montenegro, eje de la acción dramática, presenta una situación social: el fin de la hidalguía que conlleva, en la medida en que representa unas formas de vida concretas, la destrucción de una sociedad de castas, tal como revelan sus hijos (si exceptuamos al más joven de los seis, Miguel): individuos desprovistos ya de las virtudes que secularmente se le han atribuído a su grupo social y en conflicto creciente con su progenitor, hasta convertirse en ladrones del patrimonio familar y desembocar, finalmente, en el parricidio.

Como fondo coral del "héroe" y acompañando el conflicto dramático principal, está el pueblo llano, la base de la pirámide, campesinos y marineros, criados y mendigos en relación de dependencia y servidumbre con el señor tal como se esbozaba en El Marqués de Bradomín.

Juan Manuel Montenegro es el representante, pues, de esa hidalguía de rancio abolengo, que en esta sociedad campesina se identifica por el título de "don"17, que acompaña a todos los miembros de su familia, y en el texto se le denomina también Mayorazgo y Vinculero, designaciones ya en desuso en 1876, que aluden al abolido dominio señorial, cuya conservación resulta, sin embargo, sintómática de la resistencia a su desparición. En contraste, la mayoría de los antropónimos aldeanos están ligados a la toponimia gallega ${ }^{18}$ y alternan con el abundante uso de apodos, propio de Galicia (Ramiro de Bealo, El Manco de Gondar, Liberata la Blanca, Benita la Costurera, La Pichona...).

Detengámonos en la figura del hidalgo: la crítica valleinclaniana coincide en los términos en que el escritor presenta y caracteriza al hidalgo ${ }^{19}$ : señor feudal y encarnación gigantesca de excesos bárbaros, poseedor, al mismo tiempo, de un profundo sentido del honor, de la dignidad y la libertad, un primitivo concepto de la justicia y un gran orgullo de casta.

Este esquema responde al arquetipo de la nobleza feudal, que en una sociedad de corte tradicional es el elemento básico del orden social, por ello Valle la presenta como símbolo y síntesis de valores y virtudes (dignidad, sentido del honor, nobleza, generosidad...), antagónicos a los contravalores que imputa a la burguesía (materialismo, ambición, vulgaridad...). Ahora bien, al disolverse las instituciones que protegían su continuidad y garantizaban el cumplimiento de sus funciones sociales, sus protagonistas quedan reducidos a símbolos puramente 
evocadores de tiempos pasados. Y ello se produce cuando las nuevas clases sociales, nacidas de la revolución burguesa, tomen definitivamente el relevo social, es decir, en la primera mitad del XIX.

Siendo esto así en términos generales, en la Galicia de 1876 y, por ello, en las $C B$ esta figura no había sido desplazada totalmente del lugar privilegiado que durante siglos había ocupado en el mundo social campesino, y mejor que nadie resume las características de la sociedad patriarcal, cristiana y tradicional que Valle recrea en estas obras con la nostalgia y la rebeldía de lo inevitablemente destruido. Veamos, pues, el papel del hidalgo en esta sociedad agraria.

Esta figura, como se vislumbraba en el $M B C R$, se presenta a lo largo de las $C B$ bajo un triple aspecto: padre, señor-amo y juez ${ }^{20}$.

La primera de las facetas citadas, la paternidad de Montenegro, tiene una doble manifestación. En primer lugar, el viejo hidalgo aparece como padre de una prole numerosa, legítima y natural, lo cual implica la figura de la esposa, tan fiel como resignada a la sucesión de "concubinas", que en este tipo de sociedades es tanto justificación del machismo, como consecuencia del dominio señorial y del consuetudinario "derecho de pernada", que se asume con perfecta naturalidad por parte de las mujeres y hasta con orgullo en el caso de los hijos bastardos. En la vida de JMM se suceden una suma de mujeres con un papel sistemáticamente subordinado al varón.

La paternidad real obedece a las pautas de la familia patriarcal. De acuerdo con ellas, “ $¡ E l$ padre es como el Dios del cielo!” $(R L, 105)$, y en virtud de ese poder sacralizado de la paternidad Montenegro ejerce sus funciones educadoras. Sin embargo, de las relaciones de don Juan Manuel con sus hijos se desprende no solo el peculiar conflicto que constituye el argumento de las $C B$, sino algo más importante: la rebeldía de los hijos contra el tradicional sistema familiar, lo que significa su desmoronamiento y con él el de la propia organización social, asentada precisamente sobre el patriarcalismo.

El acierto de Valle-Inclán consiste, a mi juicio, en inducir al lector a extraer unas conclusiones a base de un juego de contraposiciones que revelan la suplantación de la vieja sociedad por la nueva, que a sus ojos se reviste de elementos negativos. Así, don Juan Manuel, investido de los poderes que le otorga la sociedad patriarcal, no puede ejercerlos sobre sus vástagos porque ellos no los reconocen ya como principios rectores de esa sociedad en crisis.

La segunda manifestación de la paternidad montenegrina es la paterno-doméstica. Se trata de la función paternal que el personaje ejerce sobre los "súbditos" de su competencia, sus antiguos siervos. Esta vertiente tiene una evidente proyección social y, en consecuencia, no es desligable de otra de las facetas enunciadas: la de señor-amo.

El paternalismo social, que comporta una fuerte dosis de proteccionismo, va unido a la función ejemplar que se le asigna al noble en esta sociedad tradicional: "la aristocracia es como el espejo en que deben mirarse los otros órdenes (...) estímulo de formación pedagógica"²1.

Ambos -paternalismo y ejemplaridad- se asientan sobre dos pilares: por un lado, el prestigio social, que se apoya en el linaje y actúa como justificación del Privilegio, y, por otro, el sentido de responsabilidad, propio de su condición de señor natural y de cristiano.

Don Juan Manuel, como quedó indicado, desciende de noble estirpe. Pero el linaje heredado no basta, tiene que ir acompañado del refrendo de las obras y el reconocimiento de los demás: "pues en el orgullo de los linajes, en el orgullo de las buenas obras, hay una perpetuidad en el tronco de las familias", dijo el propio Valle ${ }^{22}$. 
Los jóvenes Montenegro son frente a su padre el reverso de la moneda que revela y confirma la dicotomía sostenida a lo largo de las $C B$ :

$¡$ ¡Da dolor esos ejemplos en familias de tanto linaje! ¡Como se acaban las noblezas! ¡Ay, si hubieseis conocido al abuelo Don Ramón María! ¡Era el primer caballero de estos contornos, un caballero de aquellos cual ya no quedan! $(A B, 84)$.

Los hijos del Mayorazgo carecen del prestigio social que acompaña al heredado, pero usufructúan el paterno. Buen ejemplo de ello es la esc. 6, II de $R L$ : una tropa de chalanes se enfrenta con los hermanos Montenegro. La lucha, descrita con tintes épicos, se resuelve a favor de los hermanos y la razón es simple: "-iQue para eso son hidalgos y señores de torre!-” $(R L, 180)$. Los hijos de don Juan Manuel aunque no son acreedores de respeto porque "No heredaron (...) la honrada ley de los padres" $(R L, 248)$, son hidalgos, y esto es suficiente en principio para justificar su triunfo.

Al contrario que los jóvenes Montenegro, don Juan Manuel goza todavía del mismo prestigio moral y social de sus antepasados:

“En dónde dejais a mi amo? ¿Hay otro que lleve su vara más derecha lo mismo con ricos que con pobres? ¿Hay puerta de más caridad que la suya?" $(A B, 84)$.

Estas palabras de un campesino de Viana del Prior ponen de manifiesto que el viejo hidalgo conserva aún en esta sociedad de castas sus funciones tradicionales, explicitadas en esa interpelación que subraya el triple papel del noble como padre, juez y amo, el cual constituye la manifestación más contundente de las relaciones de vasallaje de ese mundo señorial.

El paternalismo social de don Juan Manuel tiene uno de sus mejores ejemplos en el episodio de los mendigos de Romance de Lobos ${ }^{23}$. Ante este grupo representativo de los sectores más marginales de esta sociedad jerarquizada ${ }^{24}$, Montenegro, frente a la actitud depredadora de sus hijos, asume el papel protector y ejemplar que todos esperan de él. Porque don Juan Manuel no solo goza del status social que lo convierte automáticamente en señor natural, sino del prestigio moral que en teoría le es inherente.

Estamos ante una sociedad estática en la que la imagen del pater-familias sugiere e implica la del señor-amo. El viejo Montenegro es aceptado como señor natural por sirvientes, súbditos vinculados y mendigos. Ese liderazgo natural es el principio sustentador del equilibrio social y el instrumento del que se vale es la caridad. Claro está que ese espíritu caritativo, que redime a quien lo ejerce, comporta la resignación por parte de aquellos que la aceptan con la misma lógica con la que asumen la desigualdad social. En este sentido, basta recordar que DJM y el Pobre de San Lázaro, el leproso que acaudilla a los mendigos, tienen una visión idéntica de las relaciones entre los pobres y los señores, sintetizada en las siguientes palabras del leproso que ilustran con elocuencia la ideología que vertebra esta sociedad tradicional:

Dios Nuestro Señor nos dará en el cielo su recompensa a todos los que aquí pasamos trabajos. Es su ley que unos sean pobres y otros ricos. Dios Nuestro Señor a 
los pobres nos manda tener paciencia para pedir limosna, y a los ricos les manda tener caridad...!Es la ley de Nuestro $\operatorname{Señor}_{i}(R L, 79)$.

Una dimensión complementaria de esta faceta de señor-amo que analizo se refiere al plano de las relaciones económicas que ilustra mejor que cualquier otro el esquema sociológico de esta Galicia preindustrial y agrarista. Hay que decir al respecto, que la perspectiva que domina en las Comedias Bárbaras excluye liberalismo y capitalismo. No es que Valle-Inclán desconozca que esas son las realidades que se imponen inexorablemente; la burguesía está en el poder y el valor principal de la nueva sociedad es el dinero, pero el escritor se aferra a aquel reducto geográfico en el que las transformaciones de la revolución liberal llegan con retraso, de ahí que, como digo, sea el plano económico especialmente significativo.

Son frecuentes en las Comedidas Bárbaras las alusiones a las relaciones económicas que se establecen entre el "señor" y sus criados y súbditos vinculados.

Don Juan Manuel, como hidalgo rentista, arrienda o afora sus tierras a los campesinos. Estos deben pagar al "señor" unas rentas siempre en especie y no en dinero, muestra evidente del tipo de economía tardofeudal, que sustituye la ecuación salario-trabajo, propia del capitalismo, por las prestaciones personales y el dinero por el pago en especie. A menudo aparecen en la trilogía estos campesinos, siendo el caso más ilustrativo de esta relación el del molinero Pedro Rey de $A B$, a quien el Mayorazgo perdona "la renta de este año" $(A B, 68)$. Esa prueba de magnanimidad señorial tiene una contrapartida, Liberata la Blanca, mujer de Pedro Rey, hecho que tácitamente es aceptado por el Molinero a cambio de otras compensaciones.

Por otra parte, estas relaciones de dependencia con el "señor" se extienden, en un orden doméstico, a los criados de don Juan Manuel que, como Micaela la Roja o Andreiña, llevan a su servicio toda su vida: "Comí su pan durante cincuenta años" $(A B, 41)$. La fidelidad y sumisión al "amo" es el rasgo que las define en pago a esa manutención. Ahora bien, la fidelidad de Andreiña -y es una diferencia fundamental con la primera- está en función de intereses personales y se orienta hacia el mejor postor: DJMM, $D^{a}$ María o los hijos de ambos, a quienes encubre en el expolio de la casa materna a cambio de un precio:

"Yo veré de servirle -dice al futuro sacerdote, don Farruquiño- Más luego no olvide la promesa que me hizo de tener a una de mis rapazas como su ama" $(R L, 145)$.

La vieja criada sabe adaptarse a las exigencias de una nueva situación que vislumbra con perspicacia. Su actitud contrasta con la de Micaela la Roja, que personifica la lealtad incondicional, y ambas vuelven a ser anverso y reverso de una crisis que Valle ofrece a base de contrastes.

Esta faceta de Montenegro señor-amo resulta paradigmática de las relaciones económico-sociales de una sociedad que responde a un modelo inequivocamente tradicional, cuya imagen adquiere su perfil definitivo con la tercera vertiente que caracteriza al Mayorazgo, su papel de "juez".

Desde esta perspectiva conviene indicar que Valle-Inclán muestra una concepción del derecho o, mejor, de la administración del derecho preestatalista, que implica un predominio del 
derecho privado sobre el público. Esta situación desaparece con el establecimiento del Estado burgués, que impone a la sociedad civil el mundo del derecho frente al del privilegio.

No obstante, la sicología del régimen señorial sobrevive a su desaparición jurídica, y esto explica que en el seno de una sociedad ordenada ya por una concepción jurídica moderna, don Juan Manuel actúe como juez en su feudo: señor de torre y señor de horca y cuchilla, de jurisdicción militar y civil, el mayorazgo desde su situación de privilegio resuelve pleitos e impone prohibiciones efectivas (el ancestral "derecho de paso" que crea el conflicto en Cara de Plata) y goza de una especie de "inmunidad" que le otorga su clase social.

La escena que se desarrolla en $A B$ entre Montenegro y el representante de la justicia, el escribano Malvido ( $A B, \mathrm{III}$, esc. 2), es elocuente de esta postura ${ }^{25}$. En ella el hidalgo se niega a colaborar con la justicia oficial en el descubrimiento de los autores del robo de su casona. Don Juan Manuel desprecia abiertamente este tipo de justicia que sustituye por la propia, con capacidad de dictar y ejecutar sentencia.:

Esa otra justicia con escribanos, alguaciles y cárceles, no niego que sea una invención buena para las mujeres, para los niños y para los viejos que tienen temblonas las manos, pero don Juan Manuel Montenegro todavía no necesita de ella $(A B, 129)$.

Montenegro actúa en función de unos privilegios heredados y en virtud del respaldo de una tradición que da sentido a su presente y que se niega a dar por concluída. Por eso rechaza el argumento del escribano de que los tiempos han cambiado: "Para mí son los mismos éstos que aquellos" $(A B, 128)$, responde convencido.

Valle-Inclán juega continuamente con la oposición entre el pasado y el presente que conviven en pugna en una Galicia que más que cualquier otra región española se resiste a dar el salto a la modernidad, y artísticamente lo expresa mediante la eficaz contraposición que establece entre las funciones tradicionalmente desempeñadas por la nobleza y la dificultad de ejercerlas en una sociedad a punto de disolverse. A Valle no se le escapa que la figura del "juez" Montenegro y la vigencia de sus privilegios feudales entran en colisión con la situación real, con la transformación de la sociedad en la que los ejerce. Ese es el conflicto que revela su carácter de epígono, la prolongada agonía de unas formas de vida ya caducas pero que se superponen a las nuevas. Don Juan Manuel simboliza el fin de una época, la extinción de una raza. La mejor prueba son sus hijos y, al mismo tiempo, su reverso.

A lo largo de las $C B$ los descendientes del hidalgo -con la salvedad de Miguel, Cara de Plata- aparecen a los ojos del lector desprovistos de las virtudes tradicionales que acompañaban la figura paterna. Todos los personajes que desfilan por el escenario de estas obras consideran que los hermanos Montenegro son la deshonra de su ilustre clase, los lobos del escudo de armas; nada queda en ellos de aquella dignidad y porte que definían al padre, que los califica con frecuencia como "monstruos de mi sangre" $(R L, 218)$. En buena lógica, en el sistema que se basa en la familia patriarcal, por tanto en la continuidad, peor que el final fulminante es ese proceso degenerativo, que el viejo hidalgo reconoce con dolor ${ }^{26}$.

La descendencia de Montenegro no permite albergar demasiadas esperanzas de continuidad. Los hijos, como hemos visto a través de los ejemplos espigados, son individuos inmorales en 
los que la idea del prestigio que en el padre se fundamentaba en la calidad moral, es simple indicador de posición social, vaciado de toda exigencia moral. El robo de la casona, capitaneado por don Pedrito y una cuadrilla de bandidos, la pelea entre hermanos por la herencia materna 0 el despojo de la capilla de Flavia, por no referirme al parricidio, son botones de muestra de esa degradación moral de la última generación montenegrina. Mediante este proceso degradante Valle-Inclán subraya la extinción de la sociedad del Antiguo Régimen y con ella el ocaso definitivo de la nobleza.

Valle, sin embargo, no vierte su crítica contra esa última generación. Los hijos de don Juan Manuel son en realidad las víctimas de un proceso histórico irreversible y la censura del autor -insisto en ello- no los elige como blanco, aunque las apariencias los señalen como tal. Por el contrario, a través de esas contrafiguras del protagonista, Valle muestra las consecuencias de un sistema capaz de subvertir todos los valores tradicionales de los que la hidalguía era depositaria. De esta forma la eficacia de su impugnación reside en presentar a esos personajes desclasados y, por tanto, próximos a los contravalores de su detestada burguesía, tan alejados de la moralidad, el temple y la dignidad con que el autor ha investido a la hidalguía en su principal representante, DJMM.

Quiero decir que lo que ofrece en sus $C B$ son precisamente los efectos devastadores que las medidas socio-económicas liberales producen en una sociedad tradicional como la gallega. No es casual que Valle haya puesto en boca del Sr. Ginero, esbozo de la nueva burguesía, el pronóstico amenazante de un relevo social históricamente inevitable:

Todos esos fueros de soberbia son humo, y lo serán más. Se abajan los adarves y se alzan los muladares ¡Raza de furiosos, raza de déspotas, raza de locos, ya vereis el final que os espera, Montenegros! $(A B, 155)$.

Estas palabras son anuncio inequívoco de esa nueva realidad social que convierte en sectores marginales a estos grupos sociales, en anacrónicas figuras en un mundo cuyo valor primordial es el dinero.

En conclusión, Valle-Inclán ofrece a través de las $C B$ una visión estilizada, en clave épica, de una realidad histórico-social que en sus líneas generales se corresponde con la gallega del siglo XIX, sobre la que se proyecta con singular tenacidad la sombra del Antiguo Régimen. Ese mundo agrario, precapitalista, patriarcal y cristiano responde a una imagen profundamente tradicional que se resquebraja ante el empuje de la nueva sociedad liberal, burguesa y capitalista. El escritor no realiza una crítica directa al liberalismo, que ni siquiera se menciona en los textos. Valle de forma hábil muestra sus efectos destructores sobre la sociedad tradicional. Es decir, muestra negativamente el nuevo sistema de valores de la incipiente sociedad a través de subrayar la degeneración de los antiguos, y lo hace a base de un juego de contraposiciones que tiene como elemento positivo a DJMM, cuya personalidad genera siempre de manera contrapuntística una réplica negativa, sus hijos, y cuya triple función social -padre, señor y juez- aparece contrarrestada por una realidad que la desmiente 0 , al menos, la pone en entredicho.

En efecto, en las $C B$ la caridad sustituye a la justicia social, las prestaciones económicas señoriales suplantan a la ecuación capitalista salario-trabajo, el pago en especie domina sobre la retribución en dinero y el ejercicio de la justicia pública todavía se supedita a la práctica 
del derecho consuetudinario y de la justicia exenta. Todos estos elementos, que conviven en conflicto, revelan la existencia de una crisis, la pugna entre dos mundos, y el escritor se siente solidario de aquello que está a punto de desaparecer (la razón última de esta visión hay que buscarla en el radical antiburguesismo del autor, que define su postura ideológica tradicionalista ${ }^{27}$ ) y que mejor que nadie representan esos hidalgos desposeídos de sus ancestrales privilegios y formas patrimoniales de vida, emblemáticamente encarnados en Don Juan Manuel Montenegro.

\section{Notas}

1. Vid. J. Alberich, "Sobre la configuración literaria de Don Juan Manuel Montenegro", BBMP, LIX, enerodiciembre, 1983, donde rastrea las posibles fuentes literarias de las que se sirvió Valle-Inclán para construir su personaje.

Valle juega con los datos de sus ficciones siguiendo frecuentemente una ordenación del tiempo intrínseco inverso al de escritura de sus obras. El ciclo de las Sonatas se inicia con la de Otoño (1902) y desde ahí, temporalmente hacia atrás, escribe las de Estío y Primavera; y cuando parece haber decidido cerrar la serie de las "Memorias del Marqués de Bradomín", publica La Corte de Estella en la prensa (El Imparcial, 15 de mayo al 7 de agosto de 1905), cuyo título reconvertirá poco después en Sonata de Invierno, la cual inaugura el ciclo bélico carlista propiamente dicho. Una vez más, como si se tratase de una nueva fase, desde el final de la guerra, marco temporal de la cuarta Sonata, Valle se remontará a episodios anteriores en las obras del mismo tema que sucesivamente escriba. Esta distribución no significa, sin embargo, que exista una ordenación cronológica que permita establecer una relación coherente entre las obras citadas.

Si bien esto es cierto, conviene matizar que en Los Cruzados de la Causa (1908) la reaparición de Juan Manuel Montenegro adquiere un significado político-ideológico preciso, al quedar integrado en uno de los sectores sociales que se definen por un pensamiento de corte tradicionalista, aunque Montenegro, a diferencia de Bradomín, no es tipificado como carlista (Vid. M. Santos Zas, Tradicionalismo y literatura en Valle-Inclán (1889-1910), Colorado-Boulder, Society of Spanish and spanish-american Studies, 1993 (en particular cap. XI).

Se publicó con un prólogo de Murguía en la colección Femeninas (Seis historias amorosas), Pontevedra, Imp. Landín, 1895 (utilizo la ed. de Espasa-Calpe, Austral, Madrid, 1978, que reproduce la primera). Como la mayoría de los relatos de Valle, se reeditó sucesivas veces: en La Ilustración Española y Americana, en dos episodios correspondientes al núm. XL (30-X-1903) y XLI (8-XI-1903); en Jardín Novelesco (1905), bajo el título de Don Juan Manuel (este relato no tiene nada que ver con el aparecido en El Imparcial (23-IX-1901), de igual título, que en buena parte pasó a la Sonata de Otoño, 1902). De nuevo con el título original se publica en Historias Perversas (1907) y en Historias de amor (1909); asimismo en Jardín Umbrío (1914 y 1920); en La Novela Corta, núm. 108 (26-I-1918); en Nuevo Mundo, núm. 1730 (18-III1927); y, por último, en Flores de Almendro (1936).

Vid. supra nota 4.

Las citas textuales, cuyas páginas se indican entre paréntesis, proceden de la primera edición de $E l$ Marqués de Bradomín. Coloquios Románticos, Madrid, Lib. Pueyo, Tip. de Archivos, Bibliotecas y Museos, 1907. En adelante, MBCR.

Cfr. J.M. Lavaud, “El Marqués de Bradomín: coloquios románticos. Análisis de una modalidad de creación”, Hispanística XX: Leer a Valle-Inclán en 1986, Université de Dijon, 1987, pp. 125-149.

Aguila de Blasón: Comedia bárbara dividida en cinco jornadas, Barcelona, F. Granada y Ca., Editores, 1907, por la que citaré en adelante bajo las siglas $A B$.

Véase J.M. Lavaud, El teatro en prosa de Valle-Inclán (1899-1914), Barcelona, PPU, 1992. Cfr. igualmente el estudio de J. Serrano, "La génesis de Aguila de Blasón", Boletín de la Fundación Federico García Lorca, 7-8, 1990, pp. 83-121. 
10. Aguila de Blasón. Novela en cinco jornadas, fue publicada por entregas en España Nueva entre el 17 de septiembre y el 30 de diciembre de 1906. El subtítulo de esta obra, su prehistoria en conjunto, remite, entre otros, al problema de la delimitación de su género (los términos de este debate y sus implicaciones pueden verse en L. Iglesias Feijoo, "Valle-Inclán entre teatro y novela", Diálogos Hispánicos, 7, 1988, pp. 65-79; véase del mismo "El estreno de Aguila de Blasón en 1907", en Homenaxe ó Profesor Constantitno García, Santiago, Universidad, 1991, pp. 459-471. En este sentido, Aguila de Blasón es un claro exponente de esa borrosa frontera genérica, constitutiva de la obra de Valle, que aquí solo cabe mencionar (vid. M. Santos Zas (coord.), "Estéticas de Valle-Inclán", Insula, 531, marzo, 1991).

11. Romance de Lobos: Comedia bárbara dividida en cinco jornadas, Madrid, Gregorio Pueyo, Editor, 1908 ( 25 de enero). Aunque en el título de esta primera edición figuren cinco actos, la obra consta, como es sabido, tan solo de tres. Este desajuste se solventa en la edición de 1914 de la Opera Omnia. Citaré en adelante por la primera edición bajo las siglas $R L$.

12. Ante la cuestión de la unidad de la trilogía "bárbara" se perfilan dos posiciones críticas: frente a quienes la ponen en duda (J. Alberich, "Cara de Plata fuera de serie", BHS, LXV, 1968, pp.299-308; o S. Greenfield, Ramón del Valle-Inclán: anatomía de un teatro problemático, Madrid, Fundamentos, 1972, 2ª ed. revisada, Taurus, Madrid, 1990), a cuyas consideraciones me sumo (M. Santos Zas, "A vuela pluma: la unidad de las Comedias bárbaras", El Correo Gallego, "Homenaje a Valle-Inclán", 28-VI-1986) ; otros ven las tres obras como una unidad inseparable (cfr. A. Matilla, "Las Comedias bárbaras, una sola obra dramática", en A. Zahareas et al., Ramón del Valle-Inclán: An Appraisal of his Life and Work, New York, Las Americas, 1968, pp. 289-316; o C. Porrúa, La Galicia decimonónica en las "Comedias bárbaras", Sada-A Coruña, Ediciós do Castro, 1983).

13. Cfr. la primera de las catorce entregas que forman el folletín de España Nueva, correspondiente al 17-IX1906.

14. Un desarrollo amplio de estas relaciones puede verse en mi libro citado supra nota 3 (vid. en particular, cap. VII, en el que también se indican las deudas con otros estudios que comparten este enfoque socio-histórico de las $C B$ ).

15. Esta carta de Valle-Inclán a Rivas Cherif, la inclyó éste en su artículo, "La comedia bárbara de Valle-Inclán" (España, 16 de febrero de 1924, cito por D. Dougherty, Un Valle-Inclán olvidado: entrevistas y conferencias, Madrid, Fundamentos. 1983, p. 147). En términos similares reproduce estas declaraciones F. Madrid, La vida altiva de Valle-Inclán, Buenos Aires, Poseidón, 1943, p. 151).

16. Comparto la opinión de Maravall ("La imagen de la sociedad arcaica en Valle-Inclán", Revista de Occidente, 44-45, oct.-dic., 1966, p. 232), cuando afirma que "Valle-Inclán no es un restaurador arqueológico del pasado... tampoco un historiador ni nada parecido. Es un tradicionalista a lo vivo", y con esta expresión quiere indicar el modo en que el escritor se enfrenta al pasado y su valoración del mismo: lo que ha sido, para Valle, sigue siendo, lo cual no está reñido con su declarado testimonialismo.

17. En la composición interna de la sociedad del Antiguo Régimen el linaje permite conocer a los privilegiados, quienes por la propia constitución jurídica de la sociedad tardofeudal gozaban de exenciones y privilegios. A este grupo pertenece la nobleza laica, y dentro de ella hay que situar una nobleza menor escasamente titulada, pero igualmente privilegiada que es la hidalguía, cuyas casas se remontan al siglo XVI. Su forma social de reconocimiento es el título de "don" (cfr. R. Villares, La propiedad de la tierra en Galicia, 1500-1936, Madrid, Siglo XXI, 1985, p. 115)

18. Cfr. J. Alberich, Op. cit. (nota 1), p. 310.

19. Los valores y virtudes de este tipo de personajes valleinclanescos han sido sintetizados por G. Gómez de la Serna "Ideas e ideales permanentes de Don Ramón María”, La Estafeta Literaria, junio-julio, 1965, p. 36.

20. Esta triple faceta ha sido señalada por J.A. Gómez Marín (La idea de sociedad en Vale-Inclán, Madrid, Cuadernos Taurus, 1967), cuyos planteamientos en líneas generales comparto. 
21. E. Gil y Robles, Tratado de Derecho Político según los principios de la Filosofía y el Derecho cristianos, Salmanca, 1899, t. I, p. 455.

22. Cfr. la conferencia que Valle pronunció el 1 de julio de 1911 en el Círculo Tradicionalista de Barcelona (cito por Ramoneda Salas, "Una estancia de Valle-Inclán en Barcelona", Rev. de Literatura, 102, 1989, p. 511).

23. Han glosado esta relación desde una perspectiva interpretativa épico-cristiana, pero con un enfoque eminentemente literario, S. Greenfield, Op. cit., 1990, pp. 92 y ss.); y desde el mismo ángulo pero con una dimensión sociológico-histórica mucho más próxima a la mía, J.A. Maravall, $O p$. cit., pp. 240 y ss.; J.A. Gómez Marín, Op. cit., pp. 35 y ss., C. Porrúa, Op. cit., pp. 170 y ss.; y J. M. Lavaud, "Literatura e ideología: leer Romance de Lobos en 1908", en Estudios sobre Historia de España. Homenaje a Tuñón de Lara, Madrid, U.I.M.P., 1981, pp. 341-354, t. III, entre otros.

24. En la perspectiva histórica de la sociedad precapitalista, los mendigos están integrados en ella en tanto ese mundo los necesita para mantener su orden social, para que el rico pueda ejercer su caridad y el pobre pueda mostrar sometimiento y gratitud (vid. García Pelayo, "Sobre el mundo social en la literatura de Valle-Inclán”, Revista de Occidente, 44-45, 1966, pp. 278-282, y C. Porrúa, Op. cit., pp. 170-173). Los mendigos que presenta Valle responden a esta realidad social.

25. Ya en Sonata de Otoño y en MBCR don Juan Manuel hace gala de este sentido de la justicia, cuando anuncia su intención de apalear a un escribano.

26. Cfr. el diálogo entre el Mayorazgo y don Manuelito, el capellán del pazo, en $A B$, p. 139.

27. Sobre el tradicionalismo de Valle-Inclán y su vinculación con el movimiento carlista vid. el estudio citado supra, nota 3 . 
I 